\title{
A sustainable approach for the extraction of cholesterol-lowering compounds from an olive by-product based on $\mathrm{CO}_{2}$-expanded ethyl acetate
}

\author{
Romy Vásquez-Villanueva ${ }^{1,2}$ - Merichel Plaza ${ }^{1,3}$ - María Concepción García ${ }^{1,3}$. Charlotta Turner ${ }^{2}$. \\ María Luisa Marina ${ }^{1,3}$
}

Received: 10 April 2019 / Revised: 25 May 2019 / Accepted: 7 June 2019 / Published online: 6 July 2019

(C) The Author(s) 2019

\begin{abstract}
Olive (Olea europaea) processing results in large amounts of by-products that contain valuable molecules such as phenolic compounds and phytosterols. These molecules have demonstrated to reduce blood cholesterol levels. This work proposes the development of a method to obtain simultaneously phenolic compounds and phytosterols from the olive stone using $\mathrm{CO}_{2^{-}}$ expanded liquid extraction. Hansen solubility parameters were employed for the theoretical prediction of the most suitable bio-based solvent to extract target compounds. The Box-Behnken experimental design was employed to select the optimal conditions of pressure (8-25 MPa), the molar fraction of $\mathrm{CO}_{2}$ in ethyl acetate $(0.15-0.55)$, and the temperature $\left(40-80{ }^{\circ} \mathrm{C}\right)$. Extracts showing the highest and the lowest reductions of micellar cholesterol solubility capacity were analyzed by gas chromatography coupled to mass spectrometry to find out the compounds responsible for this activity. Different phenolic compounds, free fatty acids, and phytosterols were identified in the extracts. $\beta$-Sitosterol and, especially, tyrosol and hydroxytyrosol were the compounds that primarily contributed to the reduction of micellar cholesterol solubility capacity.
\end{abstract}

Keywords Bio-based solvents $\cdot$ Cholesterol-lowering capacity $\cdot \mathrm{CO}_{2}$-expanded liquid $\cdot$ Hansen solubility parameters $\cdot$ Olive seed $\cdot$ Phenolic compounds $\cdot$ Phytosterols

\section{Introduction}

There is an increasing interest for obtaining bioactive compounds from natural sources for the elaboration of functional

Electronic supplementary material The online version of this article (https://doi.org/10.1007/s00216-019-01970-4) contains supplementary material, which is available to authorized users.

Charlotta Turner

charlotta.turner@chem.lu.se

$\triangle$ María Luisa Marina

mluisa.marina@uah.es

1 Departamento de Química Analítica, Química Física e Ingeniería Química, Universidad de Alcalá, Ctra. Madrid-Barcelona Km. 33.600, 28871 Alcalá de Henares, Madrid, Spain

2 Department of Chemistry, Centre for Analysis and Synthesis, Lund University, P.O. Box 124, 22100 Lund, Sweden

3 Instituto de Investigación Química Andrés M. del Río, Universidad de Alcalá, Ctra. Madrid-Barcelona Km. 33.600, 28871 Alcalá de Henares, Madrid, Spain foods, nutraceuticals, pharmaceuticals, and cosmeceuticals. On the other hand, food industry by-products constitute an important problem from environmental and economic points of view. However, some food industry by-products are cheap and natural sources of compounds with valuable functional properties that can be of interest for the food industry itself and for the pharmaceutical and cosmetic industries $[1,2]$.

Olive processing generates a large amount of by-products which are made up basically of leaves, wood, peel, and stones which tend to be underused and undervalued [3]. Several studies reported the potential reuse of olive stones for animal feeding, composting, and biofuel and energy production because of their high protein and oil content [4-6]. Additionally, recent researches proposed a new strategy for exploiting olive stones. This strategy is based on the extraction of olive stone proteins followed by their hydrolysis to obtain valuable peptides with antioxidant, antihypertensive, antitumoral, and hypocholesterolemic properties [7-9]. Another important part of the olive seed is its oil fraction. Olive seed oil presents an interesting nutritional profile due to the presence of fatty acids, vitamins, carotenoids, phytosterols, phenolic compounds, and 
other compounds, which have a significant role in aroma and in the chemical properties of olive [10]. The consumption of these compounds is linked to the prevention and/or reduction of the metabolic syndrome risk (which includes obesity, hyperglycemia, dyslipidemia, and hypertension diseases) [11]. Olive seed oil has been extracted using conventional methodologies requiring high amounts of polluting organic solvents [12]. Therefore, the development of sustainable extraction methods using nonpolluting solvents is highly desirable. The selection of a suitable bio-based solvent to simultaneously extract phenolic compounds and phytosterols constitutes a great challenge since these compounds present very different polarities. Indeed, phytosterols possess mainly nonpolar behavior, while phenolic compounds possess a higher solubility in intermediate polarity solvents, rather than polar or nonpolar solvents. Moreover, the intermolecular forces between phenolic compounds and solvents depend on the number of hydroxyl groups [13].

$\mathrm{CO}_{2}$-expanded liquid (CXL) extraction is an advanced extraction technique in which a solvent is pressurized with $\mathrm{CO}_{2}$ and is volumetrically expanded $[14,15]$. The addition of a compressed gas in an organic solvent could improve the extraction process. Indeed, solvent expansion modifies both solvent characteristics and physical properties. It reduces the relative permittivity as well as the hydrogen-bonding abilities of the solvent, it improves mass transfer through the reduction of solvent viscosity, and thus, it increases solute diffusivity and decreases interfacial tension. In addition, the use of CXLs can lead to a general reduction in the use of solvents even "up to $80 \%$ " [15]. These improvements will depend on the temperature, pressure, and proportion of $\mathrm{CO}_{2}$ in the organic solvent. The use of CXLs in extraction processes has not been studied in depth. In fact, there are few works in the literature that describe the use of CXLs based on methanol for the extraction of lipids [16] and based on ethanol for the extraction of astaxanthin [17], carotenoids [18], $\gamma$-linolenic acid [19], and monoterpenes [20]. These works have revealed the great potential of the extraction with CXLs as a green extraction technology.

A sustainable extraction process also requires the use of nonpolluting solvents. "Green" solvents should be inexpensive, easily removed, nontoxic, environmentally benign, biodegradable, and obtained from renewable feedstock [21]. Bio-based solvents are promising "green" solvents since they are derived from renewable sources, generally agricultural crops or residual organic matter considered as waste. For instance, during the fermentation of waste sugars, it is possible to obtain ethanol, ethyl acetate, or ethyl lactate; other solvents can be obtained from chemical conversion of lignocellulosic waste such as 2-methyltetrahydrofuran or methanol, or from cooking oil waste such as glycerol, or from citrus peel such as the terpene D-limonene [22]. They constitute a remarkable alternative to petroleum-based solvents [22]. Moreover, the use of theoretical approaches for the selection of solvents, like Hansen solubility parameters (HSP), enables to reduce the number of experiments, avoiding solvent waste generation and reducing time [23]. This approach is based on a group-contribution method used to evaluate the miscibility among substances and solvents assessing the affinity among them. Despite HSP being employed for the extraction of some bioactive compounds [20, 24-27], they have never been used for the simultaneous extraction of compounds with such a different polarity as phytosterols and phenolic compounds.

Therefore, the aim of the present work was the development of a sustainable and efficient extraction method to recover compounds with cholesterol-lowering properties (i.e., phenolic compounds and phytosterols) from olive seeds. Theoretical predictive assessment of HSP was employed to select the suitable bio-based solvent to extract phenolic compounds and phytosterols. The Box-Behnken design was used to select optimal conditions to obtain extracts with the highest in vitro cholesterol-lowering capacity from olive seeds using CXL technology. Gas chromatography (GC) coupled to mass spectrometry (MS) was employed to identify those compounds responsible for this activity.

\section{Materials and methods}

\section{Materials}

Ethyl acetate was from Fisher Scientific UK (Bishop, Meadow Road, Loughborough). Ultrapure $\mathrm{CO}_{2}$ in cylinder containers with a dip tube was purchased from Air Products (Amsterdam, Netherlands). Sodium dihydrogen phosphate was from Merck (Darmstadt, Germany) and methanol $(\mathrm{MeOH})$ was from Scharlau Chemie (Barcelona, Spain). Cholesterol oxidase kit was purchased from BioAssay Systems (Hayward, CA USA). Taurocholic acid, oleic acid, phosphatidylcholine, $\mathrm{N}, \mathrm{O}$-bis(trimethylsilyl)trifluoroacetamide with trimethylchlorosilane (BSTFA + 0.1\% TMCS), tyrosol, hydroxytyrosol, $\beta$-sitosterol, and $n$-alkane standard solution $\mathrm{C}_{8}-\mathrm{C}_{40}$ were purchased in Sigma (St. Louis, MO, USA). The olives of 'Manzanilla' variety were kindly donated by FAROLIVA S.L. Company (Murcia, Spain).

\section{Olive seed sample pretreatment}

Olives were manually pitted and seeds inside olive stones were extracted with a nutcracker. Olive seeds were ground using a grinder and dried for $48 \mathrm{~h}$ using a freeze-dryer (Hetosicc, Heto Birkerød Denmark). Dried olive seed samples were stored at $-80{ }^{\circ} \mathrm{C}$ until use. 


\section{Solvent selection by Hansen solubility parameters}

HSP were employed to estimate the solubility of phenolic compounds and phytosterols in bio-based solvents. This estimation is based on the prediction of the kind of interactions established between target compounds and solvents. Three different molecular interactions were taken into account: dispersive interaction $\left(\delta_{\mathrm{D}}\right)$, that is related to Van der Waals forces and other molecular forces; polar interaction $\left(\delta_{\mathrm{P}}\right)$, that is related to dipole moment; and hydrogen-bonding interactions $\left(\delta_{\mathrm{H}}\right)$. A three-dimensional plot of HSP $\left(\delta_{\mathrm{D}}, \delta_{\mathrm{B}}, \delta_{\mathrm{H}}\right)$ results in a "solubility" sphere that enables to select a suitable solvent to extract a target compound. "Good solvents" will present HSP similar to those observed for target compounds, and solubility spheres will be close or even overlapped. The radius of this sphere is called "interaction radius" $\left(R_{0}\right)$. The distance between the sphere centers corresponding to a solute and a solvent is $R_{\mathrm{a}}$. The ratio $R_{\mathrm{a}} / R_{0}$, called relative energy difference (RED), yields valuable information on the interaction between a target compound and a solvent. A RED value $\leq 1.0$ indicates a high affinity of the target compound for the solvent, while a RED value $>1.0$ indicates a low affinity [28].

The software Hansen Solubility Parameters in Practice (HSPiP) from the official Hansen solubility parameter site [https://www.hansen-solubility.com] was used to predict the HSP. Prediction is based on physical properties and solubility parameters of target compounds. In the case of phenolic compounds and phytosterols, this information was not available and the Yamamoto-molecular break method using its simplified molecular input line entry syntax (SMILES) was employed for its estimation.

Since HSP of an organic solvent is modified by the presence of a compressed gas, corrected HSP were calculated by the approach proposed by Williams et al. [29]

$$
\begin{aligned}
& \delta_{\mathrm{D}}=\delta_{\mathrm{D}, \text { ref }}\left(\frac{V_{\text {ref }}}{V}\right)^{1.25} \\
& \delta_{\mathrm{P}}=\delta_{\mathrm{P}, \text { ref }}\left(\frac{V_{\text {ref }}}{V}\right)^{0.5} \\
& \delta_{\mathrm{H}}=\delta_{\mathrm{H}, \text { ref }}\left[\mathrm{e}^{\left(-1.32 \times 10^{-3}\left(T_{\text {ref }}-T\right)-\left(\frac{V_{\text {ref }}}{V}\right)^{0.5}\right]^{-1}}\right.
\end{aligned}
$$

where $\delta_{\mathrm{D}}, \delta_{\mathrm{P}}$, and $\delta_{\mathrm{H}}$ are the corrected HSP considering the temperature effect. $V$ is the molar volume at the desired temperature $(T)$ and pressure. All parameters with "ref" subscript $\left(\delta_{\mathrm{D}, \text { ref }}, \delta_{\mathrm{P}, \text { ref }}\right.$, and $\delta_{\mathrm{H}, \text { ref }}$, and $\left.V_{\mathrm{ref}}\right)$ are referred at room temperature $\left(T_{\text {ref }}=25^{\circ} \mathrm{C}\right)$ and atmospheric pressure.

HSP corresponding to a mixture of solvents were determined considering this equation [28],

$\delta_{\text {mixture }}=\sum \gamma_{\mathrm{i}} \delta_{\mathrm{T}, \mathrm{i}}$ where $\gamma_{\mathrm{i}}$ is the composition of every solvent in molar fraction (in percentage), and $\delta_{\mathrm{T}, \mathrm{i}}$ is the total HSP of solvent.

\section{Design of the experiments}

To optimize the influence of the temperature, pressure, and $\mathrm{CO}_{2}$ molar fraction $\left(\mathrm{X}_{\mathrm{CO} 2}\right)$ on the extraction of cholesterollowering compounds such as phenolic compounds and phytosterols, a response surface methodology was employed. The Box-Behnken design (MODDE 10.1, Sartorius Stedim Biotech, Malmö, Sweden) was selected since it is a secondorder design based on three levels. The extraction pressure ranged from 8 to $25 \mathrm{MPa}$, temperature from 40 to $80{ }^{\circ} \mathrm{C}$, and $\mathrm{X}_{\mathrm{CO} 2}$ was from 0.15 to 0.55 . Five different responses were determined in the extracts obtained under selected conditions: extraction yield (\% dry extract weight obtained/initial dry sample weight, $w / w$ ), in vitro reduction of micellar cholesterol solubility capacity assay (\%) (cholesterol-lowering capacity), and phenolic compounds, phytosterol, and free fatty acid contents (expressed as total peak area). Analysis of variance (ANOVA) was applied to evaluate the adequacy of fitted models established between temperature, pressure, and $\mathrm{X}_{\mathrm{CO} 2}$ and the different responses.

\section{$\mathrm{CO}_{2}$-expanded ethyl acetate extraction}

CXL extraction of freeze-dried olive seeds was performed using a MV-10 ASFE system (Waters Technologies, Milford, MA, USA) controlled by a ChromScope ${ }^{\mathrm{TM}}$ software (Waters Technologies, Milford, MA, USA). The system consisted of a dual piston pump for delivering $\mathrm{CO}_{2}$ and cosolvents connected with a T-junction, an oven, an automated back pressure regulator (BPR), a transfer line heated with a heat exchanger, a make-up solvent pump, and a fraction collecting module. For each experiment, the extraction cell was filled with $500 \mathrm{mg}$ of freeze-dried olive seed. $\mathrm{CO}_{2}$ and ethyl acetate were pumped at a constant flow rate $(2.0 \mathrm{~mL} /$ $\mathrm{min}$ ) and then passed through a $200-\mathrm{cm}$ preheating coil inside the oven. The pressure was controlled by the BPR. Ethyl acetate was introduced at a flow rate of $0.3 \mathrm{~mL} / \mathrm{min}$ after BPR in order to pick up all the analytes in the collecting vessel after the expansion of $\mathrm{CO}_{2}$. The extract was collected in a $25-\mathrm{mL}$ glass bottle. According to a previous kinetic study, extraction time was set at $10 \mathrm{~min}$ to ensure high extraction yield [20]. Between extractions, the system was flushed with $\mathrm{CO}_{2} /$ ethyl acetate mixture under previous extracting conditions to avoid carryover. Extracts were stored at $-80{ }^{\circ} \mathrm{C}$ until analysis.

\section{In vitro assay for the evaluation of the reduction of micellar cholesterol solubility (RMCS) capacity}

Micelles were synthesized according to the method reported by Zhang et al. [30] with slight modifications. A solution 
consisting of $0.5 \mathrm{mM}$ cholesterol, $1 \mathrm{mM}$ oleic acid, and $2.4 \mathrm{mM}$ phosphatidylcholine in $\mathrm{MeOH}$ was prepared and dried at room temperature overnight; $15 \mathrm{mM}$ phosphate buffer (pH 7.4) containing $6.6 \mathrm{mM}$ taurocholate salt and $132 \mathrm{mM}$ $\mathrm{NaCl}$ was added to the lipid blend. To form the micelles, the mixture was sonicated for $1 \mathrm{~min}$ at $95 \%$ of amplitude by using a high-intensity focusing ultrasound probe (Sonic Vibra Cell, CVX 130, Hartford, CT, USA) followed by its incubation overnight at $37^{\circ} \mathrm{C}$ in a Thermomixer Compact (Eppendorf, Hamburg, Germany). For the assay, $150 \mu \mathrm{L}$ of $10 \mathrm{mg} / \mathrm{mL}$ of sample was added to $50 \mu \mathrm{L}$ of the micelle solution, sonicated for $1 \mathrm{~min}$ at $95 \%$ of amplitude, and incubated for $2 \mathrm{~h}$ at $37^{\circ} \mathrm{C}$. The mixture was centrifuged for $10 \mathrm{~min}$ at $6000 \times \mathrm{g}$. The supernatant was collected for the determination of the cholesterol remaining in micelles using a cholesterol kit, which was based on the cholesterol oxidase method. Cholesterol in micelle was calculated by interpolation in a calibration curve obtained using cholesterol as standard. The reduction in the micellar solubility of cholesterol was calculated using the following equation:

$\operatorname{RMCS}(\%)=\left(\frac{C_{0}-C_{\mathrm{i}}}{\mathrm{C}_{0}}\right) \times 100$

where $C_{0}$ is the initial concentration of cholesterol in micelles and $C_{\mathrm{i}}$ is the concentration of cholesterol in micelles when adding the extract.

\section{Gas chromatography analysis of extractable fraction from olive seeds}

\section{Preparation of trimethylsilyl ether (TMS)-derivative compounds}

CXL seed extracts were evaporated under a gentle nitrogen stream before derivatization. Afterwards, $50 \mu \mathrm{L}$ of BSTFA (with $1 \%$ TMCS) was added to the dried residue for silylation. The mixture was vortexed for $15 \mathrm{~min}$ and heated at $80^{\circ} \mathrm{C}$ for $1 \mathrm{~h}$. After cooling, $1 \mu \mathrm{L}$ of the sample was injected into the GC system.

\section{Gas chromatography-mass spectrometry analysis}

Analyses were carried out on an Agilent GC system 7890B from (Agilent Technologies, Palo Alto, CA, USA) with a ZB5HT inferno capillary column (5\% phenyl, 95\% dimethylpolysiloxane high-temperature phase, $30 \mathrm{~m} \times 0.25 \mathrm{~mm}$ I.D., $0.25 \mu \mathrm{m}$ film thickness) from Phenomenex Inc. The system was controlled by means of Agilent MSD ChemStation software. The chromatographic separation was based on a previous method with some modifications [31]. Optimal separation conditions were as follows: $150{ }^{\circ} \mathrm{C}$ for $2 \mathrm{~min}$, then increased to $350{ }^{\circ} \mathrm{C}$ at a rate of $5{ }^{\circ} \mathrm{C} / \mathrm{min}$. The injector was heated to
$270{ }^{\circ} \mathrm{C}$ in the split mode (ratio 1:20). Helium was used as carrier gas (7 psi). MS conditions were energy $70 \mathrm{eV}$ and full scan mode from $\mathrm{m} / \mathrm{z} 50$ to 700. Identification of compounds was carried out by mass spectra analysis using NIST 05 mass spectral library, by comparison with data found in the literature, and by comparison with standards, when available. In addition, their linear retention indices (RIs) were calculated to identify compounds more accurately. To make this, a mixture of hydrocarbons ( $n$-octane to $n$-tetracontane) dissolved in $n$-hexane was used. Moreover, the relative and normalized area $(\%)$ and the total peak area of every compound were also estimated. The normalized area was calculated as follows:

$\% A=\frac{A_{\mathrm{i}}}{A_{\text {total }}} \times 100$

where $A_{\mathrm{i}}$ is the peak area of each compound and $A_{\text {total }}$ is the total area resulted in the chromatogram.

\section{Results and discussion}

This work proposes the valorization of olive seeds based on the extraction of phytosterols and phenolic compounds. These compound classes have demonstrated cholesterol-lowering properties, but they have never been simultaneously extracted from olive seeds. For that purpose, a suitable bio-based solvent will be employed.

\section{Selection of bio-based solvent using Hansen solubility parameters}

The selection of the bio-based solvent was carried out considering the main phytosterol ( $\beta$-sitosterol) and phenolic compounds (tyrosol and hydroxytyrosol) in the olive seed. Four different bio-based solvents covering a broad range of polarities were employed: ethanol, D-limonene, ethyl lactate, and ethyl acetate. Table 1 summarizes the HSP estimation for these compounds and tested solvents. Since the information on physical properties and solubility of phenolic compounds and phytosterols was not available in the HSPiP software, determination of HSP was performed considering the properties estimated from their molecular structure (SMILES) using the Yamamoto-molecular break method.

As expected, $\beta$-sitosterol $\left(\delta_{\mathrm{P}}=1.9 \mathrm{MPa}^{1 / 2}\right)$ and phenolic compounds $\left(\delta_{\mathrm{P}}=8.1 \mathrm{MPa}^{1 / 2}\right.$ and $\delta_{\mathrm{P}}=9.1 \mathrm{MPa}^{1 / 2}$ for tyrosol and hydroxytyrosol, respectively) showed very different polarities which limited the selection of a suitable bio-based solvent. HSP can be represented in a three-dimensional space enabling a visual approximation of the target compounds and the bio-based solvents. Figure 1 shows the three-dimensional HSP sphere for all evaluated compounds (phenolic compounds and phytosterols) and the interaction with the different 
Table 1 Hansen solubility parameters of target compounds ( $\beta$-sitosterol, tyrosol, and hydroxytyrosol) and bio-based solvents (ethanol, D-limonene, ethyl lactate, and ethyl acetate) (at room temperature and $1 \mathrm{~atm}$ )

\begin{tabular}{|c|c|c|c|c|c|c|}
\hline Compound & SMILES & $\begin{array}{l}\text { Molar volume } \\
\left(\mathrm{cm}^{3} \mathrm{~mol}^{-1}\right)\end{array}$ & $\begin{array}{l}\delta_{\mathrm{D}} \\
\left(\mathrm{MPa}^{1 / 2)}\right.\end{array}$ & $\begin{array}{l}\delta_{\mathrm{P}} \\
\left(\mathrm{MPa}^{1 / 2}\right)\end{array}$ & $\begin{array}{l}\delta_{\mathrm{H}} \\
\left(\mathrm{MPa}^{1 / 2}\right)\end{array}$ & $\begin{array}{l}\delta_{\text {Total }} \\
\left(\mathrm{MPa}^{1 / 2}\right)\end{array}$ \\
\hline$\beta$-Sitosterol & $\mathrm{CCC}(\mathrm{CCC}(\mathrm{C}) \mathrm{C} 1 \mathrm{CCC} 2 \mathrm{C} 1(\mathrm{CCC} 3 \mathrm{C} 2 \mathrm{CC}=\mathrm{C} 4 \mathrm{C} 3(\mathrm{CCC}(\mathrm{C} 4) \mathrm{O}) \mathrm{C}) \mathrm{C}) \mathrm{C}(\mathrm{C}) \mathrm{C}$ & 436.5 & 17.1 & 1.9 & 3.0 & 17.5 \\
\hline Tyrosol & $\mathrm{C} 1=\mathrm{CC}(=\mathrm{CC}=\mathrm{C} 1 \mathrm{CCO}) \mathrm{O}$ & 122.3 & 19.3 & 8.1 & 16.8 & 26.8 \\
\hline Hydroxytyrosol & $\mathrm{C} 1=\mathrm{CC}(=\mathrm{C}(\mathrm{C}=\mathrm{C} 1 \mathrm{CCO}) \mathrm{O}) \mathrm{O}$ & 124.6 & 19.7 & 9.1 & 19.1 & 28.9 \\
\hline Ethanol & $\mathrm{CCO}$ & 58.6 & 15.8 & 8.8 & 19.4 & 26.5 \\
\hline D-limonene & $\mathrm{CC} 1=\mathrm{CCC}(\mathrm{CC} 1) \mathrm{C}(=\mathrm{C}) \mathrm{C}$ & 162.9 & 17.2 & 1.8 & 4.3 & 17.8 \\
\hline Ethyl lactate & $\mathrm{CCOC}(=\mathrm{O}) \mathrm{C}(\mathrm{C}) \mathrm{O}$ & 115.0 & 16.0 & 7.6 & 12.5 & 21.7 \\
\hline Ethyl acetate & $\mathrm{O}=\mathrm{C}(\mathrm{OCC}) \mathrm{C}$ & 98.6 & 15.8 & 5.3 & 7.2 & 18.2 \\
\hline
\end{tabular}

studied bio-based solvents. Blue dots correspond to the target compounds, $\beta$-sitosterol, tyrosol, and hydroxytyrosol, while the green spheres represent the pure bio-based solvents, ethanol, D-limonene, ethyl lactate, and ethyl acetate. Good solvents are those whose green sphere contains or is close to the blue dots of target compounds, while when blue dots are far from the green sphere, it means that target compounds are not well dissolved in the specific solvent. This figure also shows the RED values for the interaction between every compound and the pure bio-based solvent. As it can be observed in Fig. 1a, phenolic compounds were close to pure ethanol

\section{a Ethanol}

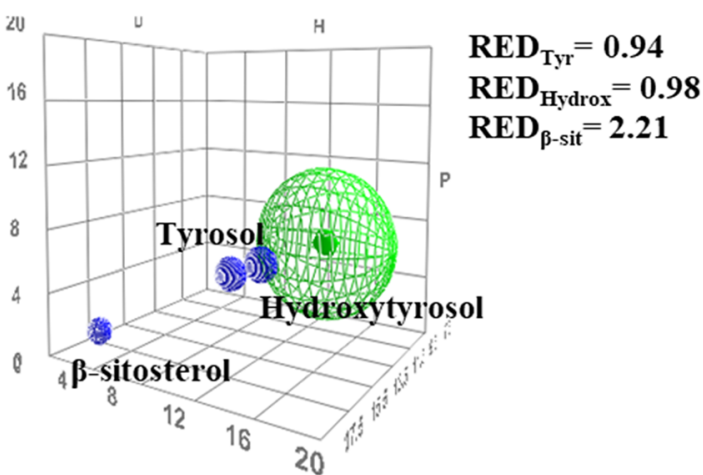

C Ethyl Lactate

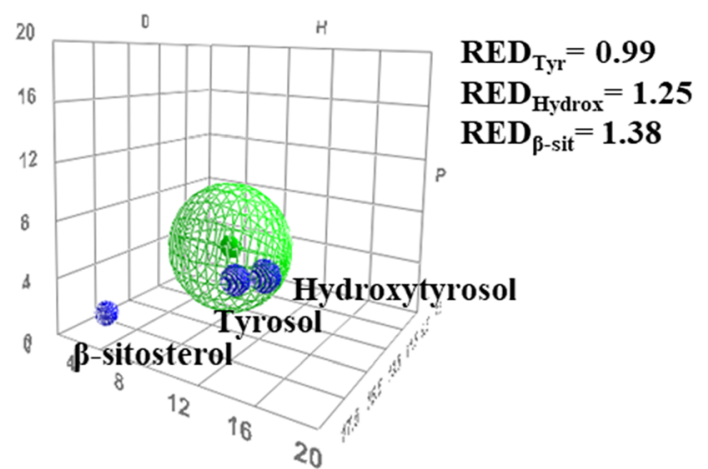

$(\mathrm{RED}<1)$, but $\beta$-sitosterol was far from the green sphere (RED > 1); thus, it was expected that ethanol can dissolve phenolic compounds but not $\beta$-sitosterol. On the contrary, D-limonene seemed to be a suitable solvent for the solubilization of $\beta$-sitosterol $(\mathrm{RED}<1)$, but it was not useful for the solubilization of phenolic compounds (RED $>1$ ) (see Fig. 1b). Finally, ethyl lactate and ethyl acetate seemed to offer a commitment between the solubility of phytosterols and phenolic compounds. In the case of ethyl lactate, phenolic compounds were close to the solvent, showing RED values of 0.99 and 1.25 ; meanwhile, $\beta$-sitosterol likely had a lower

\section{b D-Limonene}

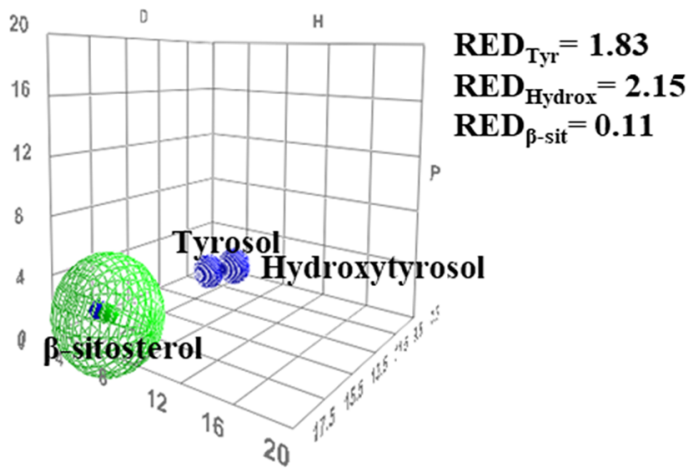

\section{d Ethyl Acetate}

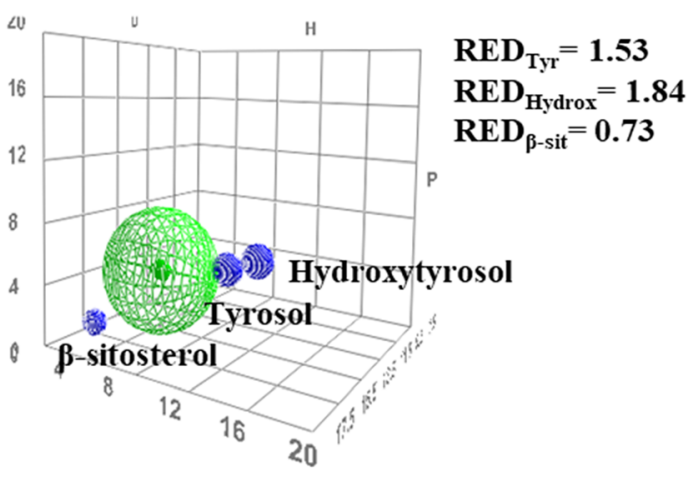

Fig. 1 Three-dimensional representation of Hansen solubility spheres corresponding to $\beta$-sitosterol, tyrosol, and hydroxytyrosol (blue dots) and to solvents (green spheres) ethanol (a), D-limonene (b), ethyl lactate (c), and ethyl acetate (d). RED values are provided in every figure 
solubility, presenting a RED value of 1.38 (Fig. 1c). For ethyl acetate, $\beta$-sitosterol exhibited a RED value of 0.73 , while tyrosol and hydroxytyrosol displayed RED values of 1.53 and 1.84, respectively (Fig. 1d).

The boiling point of ethyl acetate $\left(77.1^{\circ} \mathrm{C}\right)$ is lower than that of ethyl lactate $\left(154^{\circ} \mathrm{C}\right)$; thus, ethyl acetate is easily evaporated and it has been successfully applied for the extraction of phenolic compounds from olive residues [32]. It was the bio-based solvent finally selected. In fact, ethyl acetate was considered as an efficient solvent for the recovering of low and medium molecular weight phenolic compounds [32, 33].

\section{Optimization of the extraction of cholesterol-lowering compounds employing $\mathrm{CO}_{2}$-expanded ethyl acetate}

Once ethyl acetate was selected to extract phytosterols and phenolic compounds, the effect of the addition of $\mathrm{CO}_{2}$ was evaluated. For this purpose, the influence of the temperature $\left(40-80^{\circ} \mathrm{C}\right)$, pressure $(8-25 \mathrm{MPa})$, and molar fraction of $\mathrm{CO}_{2}$ in ethyl acetate $\left(\mathrm{X}_{\mathrm{CO} 2}\right)(0.15-0.55)$ on two response variables (extraction yield and in vitro RMCS capacity) was evaluated. The temperature, pressure, and $\mathrm{X}_{\mathrm{CO} 2}$ in ethyl acetate were chosen since they control the solubility in CXL extractions. The values investigated for these variables were established based on the phase diagrams of the binary systems $\left(\mathrm{CO}_{2}\right.$-ethyl acetate) at different temperatures, estimated by the software GPEC (see Electronic supplementary material (ESM) Fig. S1) [34]. Selected ranges for temperature, pressure, and $\mathrm{X}_{\mathrm{CO} 2}$ guaranteed that binary mixtures of ethyl acetate and $\mathrm{CO}_{2}$ were in liquid state (a region where the liquid $\mathrm{CO}_{2}$ is miscible in ethyl acetate) [15]. A response surface methodology called the Box-Behnken design was employed to optimize the number of experiments required to study the influence of the three variables (pressure, temperature, and $\mathrm{X}_{\mathrm{CO} 2}$ ). Table 2 groups the 15 experiments established by the experimental design. Three of these experiments were replicated at the central point. Additionally, Table 2 also shows the extraction yields and RMCS of extracts obtained in the 15 experiments. In order to find out any correlation between these responses (extraction yield and RMCS) and the pressure, temperature, and $\mathrm{X}_{\mathrm{CO} 2}$ used in the extractions, a multiple linear regression model was applied. Table 3 shows the coefficients of the established multiple linear regression. The regression model could explain 78 and $93 \%$, respectively, of the extraction yield and RMCS variability. Moreover, the standard error (expressed as relative standard deviation (RSD)) of the regression model was below 4.8. Additionally, ANOVA was employed to evaluate the adequacy of the regression model and results were also included in Table 3. Both regression models were considered adequate since the $p$ value for the regression test was lower than 0.05 and the $p$ value for the lack-of-fit test was higher than 0.05 .
The effect of pressure, temperature, and $\mathrm{X}_{\mathrm{CO} 2}$ on the extraction yield and RMCS capacity is shown as contour plots in panels a and b of Fig. 2, respectively. According to Fig. 2a and data grouped in Table 2, the pressure was negatively correlated with the extraction yield. Moreover, a negative correlation of the extraction yield with temperature was also observed at pressures below $20 \mathrm{MPa}$, while temperature did not have any influence at higher pressures. Figure $2 \mathrm{a}$ also shows that the optimal conditions within the test range to obtain the highest extraction yields $(w / w)$ from olive seeds were as follows: the lowest pressure $(8 \mathrm{MPa})$, a temperature of $40{ }^{\circ} \mathrm{C}$, and a $\mathrm{X}_{\mathrm{CO} 2}$ of 0.15 . Under these conditions, the predicted extracted amount of solutes was $50.7 \mathrm{wt} \%$.

On the other hand, the in vitro RMCS capacity of the extracts seemed to be positively correlated with temperature, especially at lower $\mathrm{X}_{\mathrm{CO} 2}$ (see Fig. 2b). Moreover, the optimal theoretical extraction conditions to obtain extracts with the highest capacity to reduce micellar cholesterol solubility were the highest temperature $\left(80^{\circ} \mathrm{C}\right)$ and pressure $(25 \mathrm{MPa})$ and the lowest $\mathrm{X}_{\mathrm{CO} 2}(0.15)$. Under these conditions, the predicted RMCS capacity was $74.5 \%$. The conditions enabling the highest extraction yield showed the lowest RMCS capacity, and the conditions enabling the highest RMCS capacity yielded the lowest extraction yield. This can be explained by the fact that the extraction with the highest extraction yields was likely less selective, resulting in the extraction of other compounds that did not affect the RMCS. Moreover, the extract showing the highest RMCS capacity was obtained, above the critical pressure of the mixture, while the extract showing the lowest capacity was obtained, below the critical pressure of the mixture (see ESM Fig. S1). However, the solvent mixture was in a liquid state in all the experiments performed; thus, it is expected that pressure has no influence on the solvent characteristics. Nevertheless, $\mathrm{X}_{\mathrm{CO} 2}$ and temperature might have influence on the solvent behavior in terms of density and solubility. At low temperatures, the density of the mixture increases at higher $\mathrm{CO}_{2}$ content, hence increasing solvation capacity and solubility of the compounds [35]. This fact could lead to a poor selectivity in the extraction process since any compound can be solubilized in the solvent. That is why higher yields were obtained under these extraction conditions (see Table 2 and Fig. 2a). On the other hand, at high temperature and lower $\mathrm{CO}_{2}$ content, the density of the solvent mixture as well as its solvation capacity decreases [35]. In this sense, more selective extraction processes were performed getting higher RMCS capacities (see Table 2 and Fig. 2b).

In order to identify the compounds responsible for the cholesterol-lowering capacity, the extracts exerting the highest (extract obtained in experiment 10) and the lowest (extract obtained in experiment 1) RMCS capacity were next analyzed by GC-MS. 
Table 2 Experimental design obtained by Box-Behnken and total oil (yield, $\% w / w$ ), in vitro cholesterol-lowering capacity (RMCS, \%), and phenolic compounds, phytosterol, and free fatty acid (FFA) peak areas $(A)$ in the extracts obtained under the established conditions

\begin{tabular}{|c|c|c|c|c|c|c|c|c|c|}
\hline $\begin{array}{l}\text { Experiment } \\
\text { number }\end{array}$ & Run & $\begin{array}{l}\text { Pressure } \\
(\mathrm{MPa})\end{array}$ & $\begin{array}{l}\text { Temperature } \\
\left({ }^{\circ} \mathrm{C}\right)\end{array}$ & $\begin{array}{l}\text { Molar fraction } \\
\mathrm{CO}_{2}\end{array}$ & $\begin{array}{l}\text { Yield }(\% w / \\
w)\end{array}$ & $\begin{array}{l}\text { RMCS } \\
(\%)\end{array}$ & $\begin{array}{l}A_{\text {phenolic compounds }} \\
\left(\times 10^{7}\right)\end{array}$ & $\begin{array}{l}A_{\text {Phytosterol }} \\
\left(\times 10^{7}\right)\end{array}$ & $\begin{array}{l}A_{\mathrm{FFA}} \\
\left(\times 10^{9}\right)\end{array}$ \\
\hline 1 & 7 & 8.0 & 40 & 0.35 & 47.4 & 27.0 & 0.42 & 1.34 & 1.63 \\
\hline 2 & 14 & 25.0 & 40 & 0.35 & 37.7 & 32.3 & 1.21 & 1.46 & 1.54 \\
\hline 3 & 12 & 8.0 & 80 & 0.35 & 40.8 & 46.5 & 0.81 & 1.50 & 1.54 \\
\hline 4 & 11 & 25.0 & 80 & 0.35 & 38.8 & 60.6 & 1.30 & 1.48 & 1.50 \\
\hline 5 & 8 & 8.0 & 60 & 0.15 & 48.3 & 53.5 & 0.83 & 1.70 & 1.61 \\
\hline 6 & 4 & 25.0 & 60 & 0.15 & 41.6 & 52.4 & 0.85 & 1.85 & 1.72 \\
\hline 7 & 2 & 8.0 & 60 & 0.55 & 40.2 & 60.1 & 1.35 & 1.79 & 1.61 \\
\hline 8 & 1 & 25.0 & 60 & 0.55 & 37.8 & 62.3 & 1.03 & 2.22 & 1.92 \\
\hline 9 & 15 & 16.5 & 40 & 0.15 & 37.0 & 33.1 & 0.59 & 1.45 & 1.52 \\
\hline 10 & 3 & 16.5 & 80 & 0.15 & 42.5 & 72.6 & 3.45 & 1.54 & 1.52 \\
\hline 11 & 6 & 16.5 & 40 & 0.55 & 43.6 & 54.5 & 1.54 & 1.70 & 1.62 \\
\hline 12 & 5 & 16.5 & 80 & 0.55 & 41.5 & 58.6 & 1.27 & 1.88 & 1.66 \\
\hline 13 & 9 & 16.5 & 60 & 0.35 & 42.8 & 51.5 & 0.70 & 1.60 & 1.57 \\
\hline 14 & 10 & 16.5 & 60 & 0.35 & 40.6 & 41.1 & 0.52 & 1.68 & 1.59 \\
\hline 15 & 13 & 16.5 & 60 & 0.35 & 44.1 & 39.5 & 0.62 & 1.58 & 1.58 \\
\hline
\end{tabular}

\section{GC-MS characterization of CXL extracts from olive seeds}

A GC-MS method was set up based on the previous method of the research group [31]. The temperature ramp was modified since there were no peaks from 40 to $150{ }^{\circ} \mathrm{C}$. Moreover, temperature was increased until $350{ }^{\circ} \mathrm{C}$ to assure that all compounds were eluted. Figure 3 shows the GC-MS chromatograms corresponding to the extract exerting the highest RMCS capacity, experiment 10 (Fig. 3a), and to the extract exerting the lowest capacity (and higher extraction yield ( $\% w / w)$, experiment 1 (Fig. $3 b)$. Additionally, the identified compounds in both extracts with their relative area contribution (expressed as percentage of normalized areas) and the calculated RIs are summarized in Table 4. The separated compounds were identified comparing both spectral data and RIs with the theoretical ones. When available, compounds were identified by comparison with commercial standards. As observed, 23 compounds were identified which could be divided mainly into three groups: phenolic compounds, phytosterols, and free fatty acids (Fig. 3 and Table 4).

Table 3 Coefficients of the multiple linear regression models that best fitted the responses (yield, reduction of micellar cholesterol solubility (RMCS), phenolic compounds (PC), and phytosterol) with the extraction parameters (temperature, pressure, and $\mathrm{X}_{\mathrm{CO} 2}$ ) and analysis of variance (ANOVA)

\begin{tabular}{|c|c|c|c|c|c|c|c|c|}
\hline Parameters & Yield & $p$ value & RMCS & $p$ value & $\mathrm{PC}$ & $p$ value & Phytosterol & $p$ value \\
\hline Constant & 43.0857 & $4.42372 \mathrm{e}-11$ & 44.0333 & $9.51199 \mathrm{e}-07$ & -0.215732 & 0.00811178 & 1.62 & $5.27076 \mathrm{e}-07$ \\
\hline$P$ & -3.275 & 0.00493027 & 2.56251 & 0.174945 & 0.0699889 & 0.161739 & 0.0850002 & 0.0391249 \\
\hline$T$ & -1.8 & 0.0676772 & 11.425 & 0.000270002 & 0.125399 & 0.024595 & 0.0562502 & 0.12571 \\
\hline $\mathrm{X}_{\mathrm{CO} 2}$ & -0.225 & 0.798466 & 2.9875 & 0.121854 & 0.0348503 & 0.464759 & 0.13125 & 0.00782485 \\
\hline$P^{2}$ & -1.98572 & 0.150155 & -0.029164 & 0.991006 & & & 0.0362499 & 0.457877 \\
\hline$T^{2}$ & & & -2.40417 & 0.368067 & 0.148791 & 0.0560227 & -0.21125 & 0.00540606 \\
\hline $\mathrm{X}_{\mathrm{CO} 2}^{2}$ & & & 13.0708 & 0.00121182 & 0.21511 & 0.0120844 & 0.23375 & 0.00351141 \\
\hline$P \times T$ & 2.12499 & 0.115928 & & & & & -0.035 & 0.455781 \\
\hline$P \times \mathrm{X}_{\mathrm{CO} 2}$ & 2.225 & 0.102117 & & & & & 0.07 & 0.167007 \\
\hline$T \times \mathrm{X}_{\mathrm{CO} 2}$ & & & -8.85 & 0.00779712 & -0.21304 & 0.0105698 & 0.0224999 & 0.62562 \\
\hline$R^{2}$ & 0.78 & & 0.93 & & 0.818 & & 0.94 & \\
\hline RSD & 2.4 & & 4.8 & & 0.1284 & & 0.08663 & \\
\hline$p$ value (test of regression) & 0.024 & & 0.001 & & 0.012 & & 0.011 & \\
\hline$p$ value (lack of fit) & 0.152 & & 0.845 & & 0.164 & & 0.215 & \\
\hline
\end{tabular}




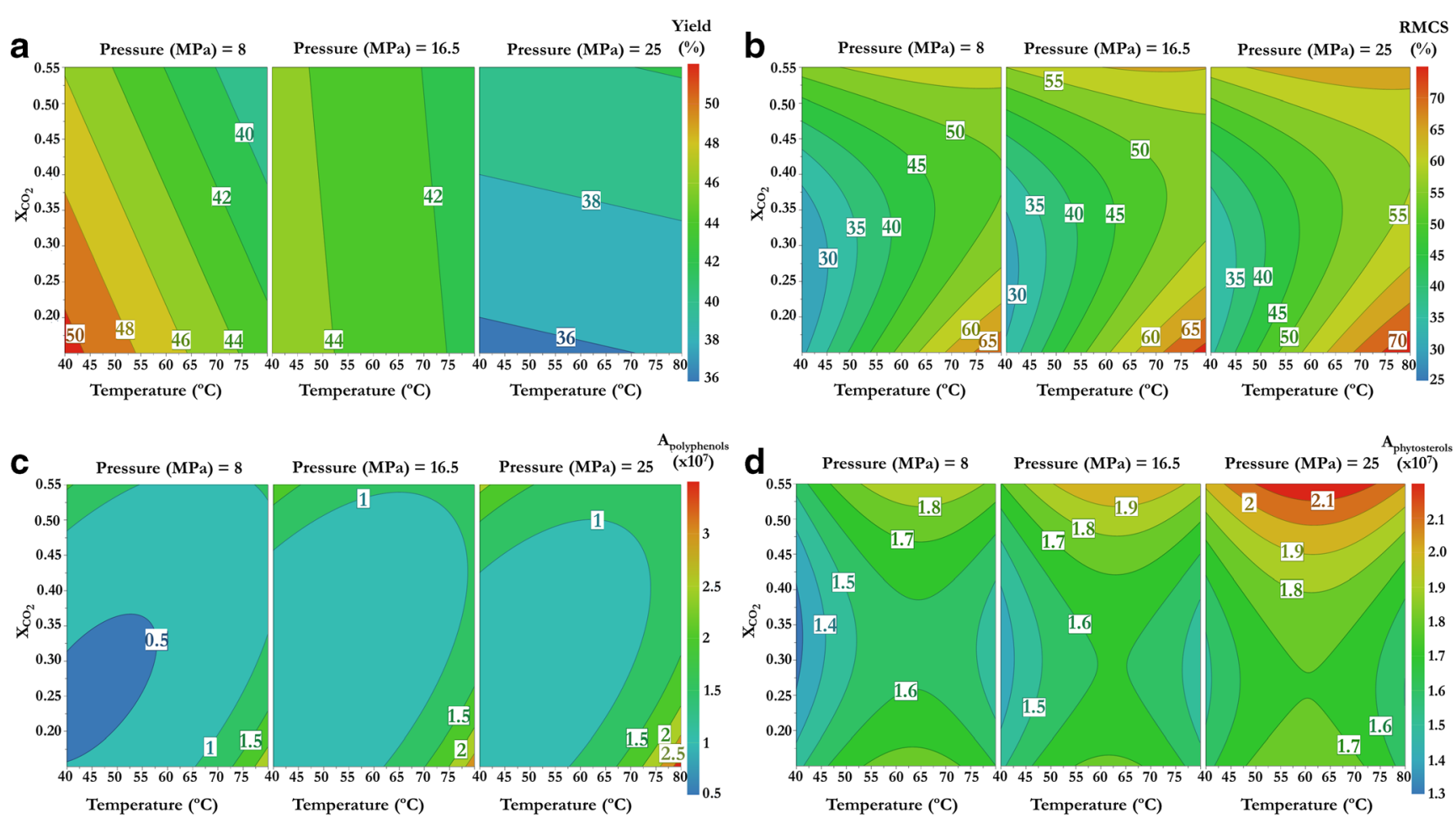

Fig. 2 Contour plots showing the effect of pressure (MPa), temperature $\left({ }^{\circ} \mathrm{C}\right)$, and $\mathrm{CO}_{2}$ molar fraction $\left(\mathrm{X}_{\mathrm{CO} 2}\right)$ on the extraction yields, \% w/w $(\mathbf{a})$; on the reduction of micellar cholesterol solubility (RMCS), \% (b); and on the phenolic compounds (c) and phytosterol (d) total peak areas

Both chromatograms showed similar profiles and main differences were observed in the areas of phenolic compounds that eluted at short retention times (from 2.5 to $6 \mathrm{~min}$ ). Three phenolic compounds were identified in the olive seed extract with the highest RMCS (experiment 10): 4-(2-hydroxy- ethyl)phenol (tyrosol, peak 2), 4-hydroxycinnamic acid ( $p$ coumaric acid, peak 3), and 4-(2-hydroxyethyl)benzene-1,2diol (hydroxytyrosol, peak 4). They are the main phenolic compounds found in olive products and olive by-products. According to their chemical structure, phenolic compounds

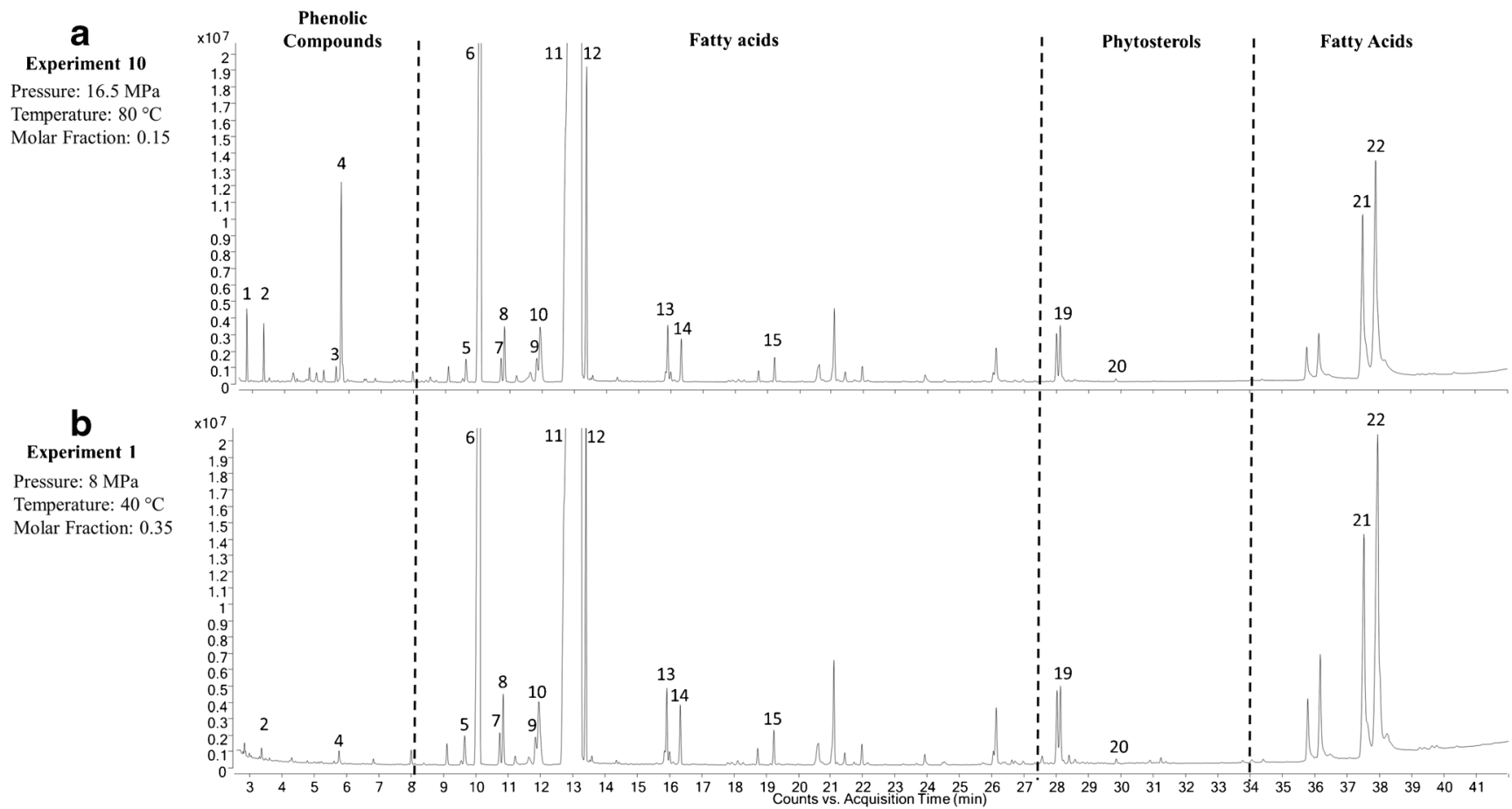

Fig. 3 GC-MS chromatograms corresponding to the most active extract (experiment 10) (a) and the least active extract (experiment 1) (b) 
Table 4 Compounds identified in the extracts showing the highest and the lowest RMCS capacity by GC-MS

\begin{tabular}{|c|c|c|c|c|c|c|}
\hline Peak & RT & RI & Compound & Formula & $\begin{array}{l}\text { Area \% } \\
\text { (experiment } 10)\end{array}$ & $\begin{array}{l}\text { Area \% } \\
\text { (experiment 1) }\end{array}$ \\
\hline 1 & 2.9 & $<1684.4$ & cis-4-Trimethylsilyloxy-cyclohexyl(trimethylsilyl)carboxylate) & $\mathrm{C}_{13} \mathrm{H}_{28} \mathrm{O}_{2} \mathrm{Si}_{2}$ & 0.41 & - \\
\hline 2 & 3.4 & $<1684.4$ & Tyrosol-TMS $(*)$ & $\mathrm{C}_{14} \mathrm{H}_{26} \mathrm{O}_{2} \mathrm{Si}_{2}$ & 0.37 & 0.10 \\
\hline 3 & 5.7 & 1684 & $p$-Coumaric acid, TMS & $\mathrm{C}_{15} \mathrm{H}_{26} \mathrm{O}_{3} \mathrm{Si}_{2}$ & 0.14 & - \\
\hline 4 & 5.9 & 1690 & Hydroxityrosol-TMS $(*)$ & $\mathrm{C}_{17} \mathrm{H}_{34} \mathrm{O}_{3} \mathrm{Si}_{3}$ & 1.70 & 0.10 \\
\hline 5 & 9.8 & 2016 & (Palmitoleic acid, $\omega-7$ )-TMS & $\mathrm{C}_{19} \mathrm{H}_{38} \mathrm{O}_{2} \mathrm{Si}$ & 0.23 & 0.22 \\
\hline 6 & 10.3 & 2029 & Palmitic acid-TMS & $\mathrm{C}_{19} \mathrm{H}_{40} \mathrm{O}_{2} \mathrm{Si}$ & 10.69 & 11.06 \\
\hline 7 & 10.9 & 2047 & 9,12-Octadecadienoic acid (Z,Z)-,methyl ester & $\mathrm{C}_{19} \mathrm{H}_{34} \mathrm{O}_{2}$ & 0.19 & 0.19 \\
\hline 8 & 11.0 & 1732 & 5-Octadecenoic acid, methyl ester & $\mathrm{C}_{19} \mathrm{H}_{36} \mathrm{O}_{2}$ & 0.42 & 0.42 \\
\hline 9 & 12.0 & 2080 & Linoleic acid ethyl ester & $\mathrm{C}_{20} \mathrm{H}_{36} \mathrm{O}_{2}$ & 0.25 & 0.23 \\
\hline 10 & 12.1 & 2083 & Ethyl linoleate / Ethyl oleate & $\mathrm{C}_{20} \mathrm{H}_{38} \mathrm{O}_{2} \mathrm{Si}$ & 0.74 & 0.78 \\
\hline 12 & 13.6 & 2233 & Stearic acid-TMS & $\mathrm{C}_{21} \mathrm{H}_{44} \mathrm{O}_{2} \mathrm{Si}$ & 2.41 & 2.46 \\
\hline 13 & 16.1 & 2413 & $\mathrm{C}(23: 1)-\mathrm{TMS}$ & $\mathrm{C}_{23} \mathrm{H}_{46} \mathrm{O}_{2} \mathrm{Si}$ & 0.48 & 0.47 \\
\hline 14 & 16.5 & 2427 & Arachidic acid-TMS & $\mathrm{C}_{23} \mathrm{H}_{48} \mathrm{O}_{2} \mathrm{Si}$ & 0.39 & 0.38 \\
\hline 15 & 19.4 & 2626 & Behenic acid-TMS & $\mathrm{C}_{25} \mathrm{H}_{52} \mathrm{O}_{2} \mathrm{Si}$ & 0.23 & 0.22 \\
\hline 16 & 20.8 & 2675 & 1-Monooleoylglycerol-TMS & $\mathrm{C}_{27} \mathrm{H}_{56} \mathrm{O}_{4} \mathrm{Si}_{2}$ & 0.56 & 0.51 \\
\hline 17 & 21.2 & 2692 & 1-Monooleoylglycerol-TMS & $\mathrm{C}_{27} \mathrm{H}_{56} \mathrm{O}_{4} \mathrm{Si}_{2}$ & 0.59 & 0.58 \\
\hline 18 & 22.2 & 2826 & Pentacosanoic acid, trimethylsilyl ester & $\mathrm{C}_{28} \mathrm{H}_{58} \mathrm{O}_{2} \mathrm{Si}$ & 0.16 & 0.14 \\
\hline 19 & 28.3 & 3272 & $\beta$-sitosterol-TMS (*) & $\mathrm{C}_{32} \mathrm{H}_{58} \mathrm{OSi}$ & 0.51 & 0.83 \\
\hline 20 & 29.4 & 3423 & 1-Monooleoylglycerol-TMS & $\mathrm{C}_{27} \mathrm{H}_{56} \mathrm{O}_{4} \mathrm{Si}_{2}$ & 0.21 & 0.16 \\
\hline 21 & 37.8 & $>3430$ & Lanosterol & $\mathrm{C}_{30} \mathrm{H}_{50} \mathrm{O}$ & 4.26 & 4.13 \\
\hline 22 & 38.2 & $>3430$ & Triolein & $\mathrm{C}_{57} \mathrm{H}_{104} \mathrm{O}_{6}$ & 3.49 & 4.88 \\
\hline
\end{tabular}

(*) Available standards

are usually found in the water-soluble parts of olive and its byproducts, but there is a small part that could also be found in the oil [36]. Among their biological properties and their health benefits are the reduction of the blood cholesterol levels and the prevention of age-related processes, chronic inflammatory disorders, some cancer diseases, and other diseases related to metabolic syndrome [11]. However, only tyrosol was found at a low intensity in the extract with the lowest in vitro RMCS (experiment 1). The difference in the phenolic abundances between both extracts (experiments 1 and 10) suggested that phenolic compounds were significant contributors to the in vitro cholesterol-lowering capacity.

HSP values were calculated for both experiments ( 1 and 10) in order to observe what parameters have affected the extraction of cholesterol-lowering compounds. HSP values in the mixture of $\mathrm{CO}_{2}$ and ethyl acetate were calculated with Eqs. (1), (2), (3), and (4). HSP for experiment 1 were $\delta_{\mathrm{D}}=$ $11.0, \delta_{\mathrm{P}}=4.3, \delta_{\mathrm{H}}=6.6$, and $\delta_{\text {Total }}=13.5$; and for experiment 10 , HSP were $\delta_{\mathrm{D}}=12.9, \delta_{\mathrm{P}}=4.8, \delta_{\mathrm{H}}=6.5$, and $\delta_{\text {Total }}=15.2$. The main differences were in $\delta_{\mathrm{D}}$ and $\delta_{\mathrm{P}}$ that they affect Van der Waals forces and polar interaction, respectively. Therefore, in experiment 10, the polar interaction and Van der Waals forces were higher than in experiment 1 favoring the extraction of phenolic compounds.
Other groups of compounds found in the olive seed extracts were free fatty acids (FFA). FFA fraction eluted in the region from 8 to $27 \mathrm{~min}$ and from 34 to $40 \mathrm{~min}$. No difference was observed in the region from 8 to $27 \mathrm{~min}$ when comparing both extracts suggesting that these compounds were not mainly responsible for the observed cholesterol-lowering capacity. Main FA in the extracts was oleic acid (peak 11), representing around $65 \%$ of total peak area in both extracts. Oleic acid is the most important monounsaturated FFA in the olive and can be present in a wide range of concentrations, from 47 to $77 \%$ $(w / w)$ of oil matter [37, 38]. The intake of unsaturated FA such as oleic acid is related to health benefits due to its capacity to reduce LDL-cholesterol in the blood [39].

Additionally, the plant sterol $\beta$-sitosterol was also identified in both extracts $(\operatorname{tr}=28.3 \mathrm{~min}$, peak 19) (see Table 4). $\beta$ Sitosterol is the most abundant plant sterol found in the vegetable kingdom. Phytosterols are compounds very similar to cholesterol structure. They are extracted from plant oil matrices and are insoluble in water. The interest in phytosterols is based on their documented cholesterol-lowering effects, antiatherogenicity effect, anticancer properties, and antioxidant and anti-inflammatory activities [40]. As can be seen in Fig. 3 and Table 4, the normalized areas of $\beta$-sitosterol in extracts 10 and 1 were around $0.5-0.8 \%$, being slightly higher in the 
extract with the lowest RMCS capacity (extract of experiment $1)$.

\section{Effect of the experimental conditions on the extraction of phenolic compounds, phytosterols, and free fatty acids}

In order to predict the experimental conditions enabling the highest extraction of phenolic compounds, FFA and $\beta$-sitosterol, the total peak area of every group of compounds obtained in the 15 experiments established by the experimental design was calculated and data were included in Table 2. Phenolic compounds and phytosterol contents were linearly correlated with temperature, pressure, and $\mathrm{X}_{\mathrm{CO} 2}$, while no correlation was observed for the FFA content. Indeed, multiple linear regression enabled to describe more than $81 \%$ of the variability of phytosterol and phenolic compound contents. Moreover, ANOVA confirmed that the established regression model was correct for these two responses. Nevertheless, there was not any significant difference among the FFA contents obtained at the tested conditions, which means that these compounds do not contribute to the RMCS capacity observed in the extracts.

Furthermore, Fig. 2c, d shows, as contour plots, the influence of extraction conditions on the phenolic compounds and phytosterol contents. At the lowest concentration of $\mathrm{CO}_{2}$, phenolic compound content was positively correlated with temperature, while pressure did not have any effect (see Fig. 2c). This could be because the solubility of phenolic compounds increases when increasing the temperature favoring their extraction [41]. Moreover, ethyl acetate presents a higher dielectric constant than $\mathrm{CO}_{2}$, and thus, the dielectric constant of the solvent at the lowest $\mathrm{X}_{\mathrm{CO} 2}$ is greater than at higher $\mathrm{X}_{\mathrm{CO} 2}$ favoring the extraction of phenolic compounds. Thus, the best conditions to extract phenolic compounds were a pressure of $25 \mathrm{MPa}$, a temperature of $80^{\circ} \mathrm{C}$, and a $\mathrm{X}_{\mathrm{CO} 2}$ of 0.15 . As can be seen, higher pressures might increase the extraction of phenolic compounds, but the pressure effect was not significant ( $p \geq$ 0.05 ) (Table 3). This fact was also observed by Prasad et al. in the extraction of phenolic compounds from longan fruit pericarp, for which more than $20 \mathrm{MPa}$ was needed to extract the highest concentration of phenolic compounds [42]. High pressures enable to increase mass transfer since the solvent can disrupt cell walls and hydrophobic bonds in the cell membranes, which lead to a high permeability [43]. Surprisingly, these conditions were identical to those predicting the highest RMCS capacity. In fact, contour plots for phenolic compounds and RMCS were very similar (Fig. 2b, c).

Unlike phenolic compounds, $\beta$-sitosterol content was positively correlated with $\mathrm{X}_{\mathrm{CO} 2}$ and pressure (Fig. 2d). This behavior could be expected since at increasing $\mathrm{CO}_{2}$ concentration in the solvent, the relative permittivity of the mixture decreases and the interactions between nonpolar compounds and the solvent are favored. Optimal extraction conditions to recover $\beta$-sitosterol were a pressure of $25 \mathrm{MPa}$, a temperature of $62{ }^{\circ} \mathrm{C}$, and a $\mathrm{X}_{\mathrm{CO} 2}$ of 0.55 . Similar to phenolic compounds, the extraction of $\beta$-sitosterol was favored at high pressures. The extract with the highest $\beta$-sitosterol content (experiment 8 ) also showed a high RMCS capacity (around 62\%) (Table 2). Moreover, the extract obtained in experiment 1 , which showed a low RMCS capacity, also presented the lowest content of both phenolic compounds and $\beta$-sitosterol, while the extract from experiment 10 , that showed a high RMCS capacity, presented the highest phenolic content and also a high $\beta$-sitosterol content. These results suggested that phenolic compounds were the main contributor to RMCS capacity and that a suitable balance between phenolic compounds and $\beta$-sitosterol may affect greatly the RMCS capacity.

\section{Conclusions}

The present work proposes a "green" methodology to extract highly cholesterol-lowering compounds from a food byproduct involving the use of $\mathrm{CO}_{2}$-expanded bio-based solvents. HSP enabled to predict that ethyl acetate was the most suitable bio-based solvent for the simultaneous extraction of cholesterol-lowering compounds of different polarities from the olive seed. The use of the experimental Box-Behnken design enabled to reduce the number of experiments to 15 to study the influence of temperature, pressure, and $\mathrm{X}_{\mathrm{CO} 2}$ on the extraction. Optimal extraction conditions to obtain the highest RMCS capacity were obtained at a pressure of $25 \mathrm{MPa}$, a temperature of $80{ }^{\circ} \mathrm{C}$, and a $\mathrm{X}_{\mathrm{CO} 2}$ of 0.15 . The analysis of extracts showing the highest and the lowest RMCS capacity by GC-MS enabled to observe that $\beta$-sitosterol and, especially, phenolic compounds were the main contributors to the cholesterol-lowering capacity observed in seed extracts. This eco-friendly strategy enables the exploitation of a sustainable source of phenolic compounds and $\beta$-sitosterol that have demonstrated to have high capacity to reduce cholesterol solubility and that could be of great interest to produce functional foods and nutraceuticals.

Acknowledgments The authors thank the Center of Applied Chemistry and Biotechnology (CQAB) of the University of Alcala for the availability of GC-MS instrumentation to achieve extract analysis.

Funding This work was supported by the Spanish Ministry of Economy and Competitiveness (ref. AGL2016-79010-R), the Comunidad of Madrid (Spain) and European funding from FSE and FEDER Programs (project S2018/BAA-4393, AVANSECAL-II-CM). R.V.-V thanks the University of Alcalá for her predoctoral contract and the grant to stay in Lund University. M.P. thanks the Spanish Ministry of Economy and Competitiveness and the University of Alcalá for her "Juan de la Cierva" (IJCI-2014-22143) and postdoctoral research contracts, respectively. C.T. acknowledges the Swedish Research Council Formas (201600604). 


\section{Compliance with ethical standards}

Conflict of interest The authors declare that they have no conflict of interest.

Open Access This article is distributed under the terms of the Creative Commons Attribution 4.0 International License (http:// creativecommons.org/licenses/by/4.0/), which permits unrestricted use, distribution, and reproduction in any medium, provided you give appropriate credit to the original author(s) and the source, provide a link to the Creative Commons license, and indicate if changes were made.

\section{References}

1. Capasso R, Cristinzio G, Evidente A, Scognamiglio F. Isolation, spectroscopy and selective phytotoxic effects of polyphenols from vegetable waste waters. Phytochemistry. 1992;31(12):4125-8.

2. El Mekawy A, Diels L, Bertin L, De Wever H, Pant D. Potential biovalorization techniques for olive mill biorefinery wastewater. Biofuels Bioprod Biorefin. 2013;8(2):283-93.

3. Roselló-Soto E, Koubaa M, Moubarik A, Lopes RP, Saraiva JA, Boussetta N, et al. Emerging opportunities for the effective valorization of wastes and by-products generated during olive oil production process: non-conventional methods for the recovery highadded value compounds. Trends Food Sci Technol. 2015;45(2): 296-310.

4. Carraro L, Trocino A, Xiccato G. Dietary supplementation with olive stone meal in growing rabbits. Ital J Anim Sci. 2005;4(3): 88-90.

5. Hernández V, Romero-García JM, Dávila JA, Castro E, Cardona CA. Techno-economic and environmental assessment of an olive stone based biorefinery. Resour Conserv Recycl. 2014;92:145-50.

6. Rodríguez G, Lama A, Rodríguez R, Jiménez A, Guillén R, Fernández-Bolaños J. Olive stone an attractive source of bioactive and valuable compounds. Bioresour Technol. 2008;99(13):5261-9.

7. Esteve C, Marina ML, García MC. Novel strategy for the revalorization of olive (Olea europaea) residues based on the extraction of bioactive peptides. Food Chem. 2015;167:72-280.

8. Vásquez-Villanueva R, Muñoz-Moreno L, Carmena MJ, Marina ML, García MC. In vitro antitumor and hypotensive activity of peptides from olive seeds. Funct Foods. 2018;42:177-84.

9. Prados IM, Marina ML, García MC. Isolation and identification by high-resolution liquid chromatography tandem mass spectrometry of novel peptides with multifunctional lipid-lowering capacity. García Food Res Int. 2018;111:77-86.

10. Alves E, Rey F, da Costa E, Moreira ASP, Pato L, Pato L, et al. Olive (Olea europaea L. cv. Galega vulgar) seed oil: a first insight into the major lipid composition of a promising agro-industrial byproduct at two ripeness stages. Eur J Lipid Sci Technol. 2018;120(4):1700381.

11. Saibandith B, Spencer JPE, Rowland IR, Commane DM. Olive polyphenols and metabolic syndrome. Molecules. 2017;22(7): 1082.

12. Moussaoui R, Labbaci W, Hemar N, Youyou A, Amir Y. Physicochemical characteristics of oils extracted from three compartments of the olive fruit (pulp, endocarp and seed) of variety Chemlal cultivated in Kabylia (Algeria). J Food Agric Environ. 2008;4(2): $52-5$.

13. Das AJ, Khawas P, Seth D, Miyaji T, Deka SC. Optimization of the extraction of phenolic compounds from Cyclosorus extensa with solvents of varying polarities. Prep Biochem Biotechnol. 2016;46(8):755-63.
14. Jessop PG, Subramaniam B. Gas-expanded liquids. Chem Rev. 2007;107(6):2666-94.

15. Akien GR, Poliakoff M. A critical look at reactions in class I and II gas-expanded liquids using $\mathrm{CO}_{2}$ and other gases. Green Chem. 2009;11:1083-100.

16. Paudel A, Jessop MJ, Stubbins SH, Champagne P, Jessop PG. Extraction of lipids from microalgae using $\mathrm{CO}_{2}$-expanded methanol and liquid $\mathrm{CO}_{2}$. Bioresour Technol. 2015;184:286-90.

17. Reyes FA, Mendiola JA, Ibañez E, Del Valle JM. Astaxanthin extraction from Haematococcus pluvialis using $\mathrm{CO}_{2}$-expanded ethanol. J Supercrit Fluids. 2014;92:75-83.

18. Gilbert-López B, Mendiola JA, Fontecha J, van der Broek LAM, Sijtsma L, Cifuentes A, et al. Downstream processing of Isochrysis galbana: a step towards microalgal biorefinery. Green Chem. 2015;17(9):4599-609.

19. Golmakani MT, Mendiola JA, Rezaei K, Ibáñez E. Expanded ethanol with $\mathrm{CO}_{2}$ and pressurized ethyl lactate to obtain fractions enriched in $\gamma$-linolenic acid from Arthrospira platensis (Spirulina). J Supercrit Fluids. 2012;62:109-15.

20. Al-Hamimi S, Abellan Mayoral A, Cunico LP, Turner C. Carbon dioxide expanded ethanol extraction: solubility and extraction kinetics of $\alpha$-pinene and cis-verbenol. Anal Chem. 2016;88:4336-45.

21. Calvo-Flores FG, Monteagudo-Arrebola MJ, Dobado JA, IsacGarcía J. Green and bio-based solvents. Top Curr Chem (Z). 2018;376(3):18.

22. Byrne F, Jin S, Sherwood J, McElroy CR, Farmer TJ, Clark JH, et al. Bio-based solvents. In: Jerome F, Luque R, editors. Solvents from waste: Wiley; 2017. p. 49-89.

23. Srinivas K, King JM, Monrad JK, Howard LR, Hansen CM. Optimization of subcritical fluid extraction of bioactive compounds using Hansen solubility parameters. J Food Eng Phys Prop. 2009;74(6):342-54.

24. Sánchez-Camargo AP, Montero L, Cifuentes A, Herrero M, Ibáñez E. Application of Hansen solubility approach for the subcritical and supercritical selective extraction of phlorotannins from Cystoseira abies-marina. RSC Adv. 2016;6(97):94884-94,895.

25. Sánchez-Camargo AP, Pleite N, Herrero M, Cifuentes A, Ibáñez E, Gilbert-López B. New approaches for the selective extraction of bioactive compounds employing bio-based solvents and pressurized green processes. J Supercrit Fluids. 2017;128:112-20.

26. Pagano I, Sánchez-Camargo AP, Mendiola JA, Campone L, Cifuentes A, Rastrelli L, et al. Selective extraction of high-value phenolic compounds from distillation wastewater of basil (Ocimum basilicum L.) by pressurized liquid extraction. Electrophoresis. 2018;39(15):1884-91.

27. Ballesteros-Vivas D, Alvarez-Rivera G, Sánchez-Camargo AP, Ibáñez E, Parada-Alfonso F, Cifuentes A. A multi-analytical platform based on pressurized-liquid extraction, in vitro assays and liquid chromatography/gas chromatography coupled to high resolution mass spectrometry for food by-products valorisation. Part 1 : withanolides-rich fractions from goldenberry (Physalis peruviana L.) calyces obtained after extraction optimization as case study. $\mathrm{J}$ Chromatogr A. 2018;164:1584.

28. Hansen CM. Hansen solubility parameters: a user's handbook; 2000. p. 1-24.

29. Williams LL, Rubin JB, Edwards HW. Calculation of Hansen solubility parameter values for a range of pressure and temperature conditions, including the supercritical fluid region. Ind Eng Chem Res. 2004;43(16):4967-72.

30. Zhang H, Yokoyama WH, Zhang H. Concentration-dependent displacement of cholesterol in micelles by hidrophobic rice bran protein hydrolysates. J Sci Food Agric. 2012;97(7):1395-401.

31. Plaza M, Santoyo S, Jaime L, Avalo B, Cifuentes A, Reglero G, et al. Comprehensive characterization of the functional activities of pressurized liquid and ultrasound-assisted extracts from Chlorella vulgaris. LWT Food Sci Technol. 2012;46(1):245-53. 
32. Lesage-Meessen L, Navarro D, Maunier S, Sigoillot JC, Lorquin J, Delattre M, et al. Simple phenolic content in olive oil residues as a function of extraction systems. Food Chem. 2001;75(4):501-7.

33. Hachicha S, Cegarra J, Sellami F, Hachicha R, Drira N, Medhioub $\mathrm{K}$, et al. Elimination of polyphenols toxicity from olive mill wastewater sludge by its co-composting with sesame bark. J Hazard Mater. 2009;161(2-3):1131-9.

34. Cismondi M, Michelsen ML. Global phase equilibrium calculations: critical lines, critical end points and liquid-liquid-vapor equilibrium in binary mixtures. Fluid Phase Equilib. 2007;259(3):22834.

35. Falco N, Kiran E. Volumetric properties of ethyl acetate + carbon dioxide binary fluid mixtures at high pressures. J Supercrit Fluids. 2012;61:9-24.

36. Nunes MA, Costa ASG, Bessada S, Santos J, Puga H, Alves RC, et al. Olive pomace as a valuable source of bioactive compounds: a study regarding its lipid- and water-soluble components. Sci Total Environ. 2018;644:229-36.

37. Zarrouk W, Baccouri B, Taamalli W, Trigui A, Daoud D, Zarrouk M. Oil fatty acid composition of eighteen Mediterranean olive varieties cultivated under the arid conditions of Boughrara (southern Tunisia). Grasas Aceites. 2009;60(5):500-8.

38. Monfreda M, Gobbi L, Grippa A. Blends of olive oil and sunflower oil: characterization and olive oil quantification using fatty acid composition and chemometric tools. Food Chem. 2012;134(4): 2283-90.
39. Binkoski AE, Kris-Etherton PM, Wilson TA, Mountain ML, Nicolosi RJ. Balance of unsaturated fatty acids is important to a cholesterol-lowering diet: comparison of mid-oleic sunflower oil and olive oil on cardiovascular disease risk factors. J Am Diet Assoc. 2005;105(7):1080-6.

40. Moreau RA, Whitaker BD, Hicks KB. Phytosterols, phytostanols, and their conjugates in foods: structural diversity, quantitative analysis, and health-promoting uses. Prog Lipid Res. 2002;41(6):457500 .

41. Benmeziane F, Djamai R, Cadot Y, Seridi R. Optimization of extraction parameters of phenolic compounds from Algerian fresh table grapes, (Vitis vinifera). Int Food Res J. 2014;21(3):1061-5.

42. Prasad KN, Yang E, Yi C, Zhao M, Jiang Y. Effects of high pressure extraction on the extraction yield, total phenolic content and antioxidant activity of longan fruit pericarp. Innov Food Sci Emerg Technol. 2009;10(2):155-9.

43. Xiang C, Xu Z, Liu J, Li T, Yang Z, Ding C. Quality, composition, and antioxidant activity of virgin olive oil from introduced varieties at Liangshan. LWT Food Sci Technol. 2017;78:226-34.

Publisher's note Springer Nature remains neutral with regard to jurisdictional claims in published maps and institutional affiliations. 